\title{
The performance of PCD tools in high-speed milling of Ti6Al4V
}

\author{
Gert Adriaan Oosthuizen • Guven Akdogan • \\ Nico Treurnicht
}

Received: 16 March 2010 / Accepted: 17 June 2010 / Published online: 10 July 2010

(C) The Author(s) 2010. This article is published with open access at Springerlink.com

\begin{abstract}
Tool performance of conventional tools is poor and a major constraint when used in milling titanium alloys at elevated cutting speeds. At these high cutting speeds, the chemical and mechanical properties of Ti6Al4V cause complex wear mechanisms. In this paper, a fine-grain polycrystalline diamond (PCD) end mill tool was tested, and its wear behavior was studied. The performance of the PCD tool has been investigated in terms of tool life, cutting forces, and surface roughness. The PCD tool yielded longer tool life than a coated carbide tool at cutting speeds above $100 \mathrm{~m} / \mathrm{min}$. A slower wear progression was found with an increase in cutting speeds, whereas the norm is an exponential increase in tool wear at elevated speeds. Observations based on scanning electron microscope (SEM) and energy dispersive spectroscopy (EDAX) analysis suggest that adhesion of the workpiece is the wear main type, after which degradation of the tools accelerates probable due to the combined effect of high temperature degradation coupled with abrasion.
\end{abstract}

Keywords Milling · Tool wear · High speed

Thermal softening $\cdot$ Ti6Al4V $\cdot$ PCD tool

G. A. Oosthuizen $(\bowtie) \cdot N$. Treurnicht

Department of Industrial Engineering, University of Stellenbosch, Private Bag X1,

Matieland 7602, South Africa

e-mail: tiaan@sun.ac.za

G. Akdogan

Department of Process Engineering, University of Stellenbosch, Private Bag X1,

Matieland 7602, South Africa

\section{Introduction}

Titanium alloys have found wide application in the aerospace and biomedical industries due to their good strength-to-weight ratio and superior corrosion resistance [1]. High-speed machining is defined whereby conventional cutting speeds are exceeded by a factor of 5 to 10 . Ti6A14V is generally difficult to machine at cutting speeds of over $30 \mathrm{~m} / \mathrm{min}$ with high-speed steel tools and over $60 \mathrm{~m} / \mathrm{min}$ with cemented tungsten carbide tools [2]. The thermal conductivity [3] of Ti6Al4V $(7 \mathrm{~W} / \mathrm{m} \mathrm{K})$ is around $1 / 25$ of that of aluminum $(6061,177 \mathrm{~W} / \mathrm{m} \mathrm{K})$. The result is a concentration of heat in the cutting zone (thermal stress), causing the characteristically high tool wear for which titanium alloys are known [1,3]. Temperatures [4] of $900^{\circ} \mathrm{C}$ have been measured at a cutting speed of $75 \mathrm{~m} / \mathrm{min}$. Titanium's chemical reactivity becomes problematic at temperatures above $500^{\circ} \mathrm{C}$. Apart from diffusion wear, it has a strong affinity to adhere, which leads to chips seizing onto the tool cutting surface. Once a built-up edge develops, tool failure follows rapidly [5]. The combination of a low [6] Young's modulus (114 GPa) coupled with a high yield stress ratio allows only small plastic deformations [1-3] and encourages deflections, chatter, and movement of the workpiece away from the tool. The thermal conductivity for PCD $(\lambda \approx 400 \mathrm{~W} / \mathrm{m} \mathrm{K})$ is roughly four times greater than that of tungsten carbide $(\lambda \approx 100 \mathrm{~W} / \mathrm{m} \mathrm{K})$ [7], and PCD is significantly harder (approximately $6,000 \mathrm{HV}$ ) than carbides (approximately 2,500 HV). The softening temperature (hot hardness) [1] of PCD is higher than that of other commercially available cutting materials, indicating better performance at elevated temperatures [8]. Research [9] showed that PCD represents a substitute tool material for turning titanium alloys and that it produced a better 
Table 1 Mechanical and physical properties of the workpiece at room temperature

\begin{tabular}{ll}
\hline Test specimen & Ti6Al4V \\
Hardness & $360 \mathrm{HV}$ \\
Ultimate tensile strength & $1,080 \mathrm{MPa}$ \\
\hline
\end{tabular}

workpiece surface integrity in finish turning operations [10]. Regardless of all these positive findings in turning, very little data exists on finish milling Ti6Al4V and even less on the rough milling using PCD. Studies [7] reported a tool life of $215 \mathrm{~min}\left(V_{\mathrm{c}}=457 \mathrm{~m} / \mathrm{min}\right)$ with PCD, concluding that highspeed milling of Ti6AlV4 is possible. Nurul Amin et al. [11] studied the effectiveness of PCD and compared it to uncoated tungsten carbide-cobalt inserts machining Ti6Al4V. The authors concluded that PCD inserts can be used effectively up to cutting speeds of $160 \mathrm{~m} / \mathrm{min}$, as the wear rate is relative low and the amount of metal removal per unit of tool life is acceptable. Similarly, research [3] reported a rather satisfactory long tool life ( $T=381 \mathrm{~min})$ with good surface finish and geometrical accuracy, finish milling titanium compressor blades with PCD at a relatively slower cutting speed $\left(V_{\mathrm{c}}=110 \mathrm{~m} / \mathrm{min}\right)$. In addition to this, research $[2,12]$ indicated that the performance of binderless cubic boron nitride $(\mathrm{BCBN})$ is a manifestation of the phenomenon envisaged in a study [7], namely that a tool material with sufficiently hot hardness will be able to yield better machining productivity through the utilization of the thermal softening of Ti6Al4V by means of an $\alpha-\beta$ phase change [13]. This counterintuitive phenomenon has been discussed in the literature $[7,13]$, and it is believed [14] that higher cutting speeds lead to decreasing cutting forces [8] if the cutting material is able to maintain its hot strength, whereas the workpiece material softens at the cutting edge, and chips can be removed more easily. In addition, Eckstein et al. [15] describe a "slower wear progression" when working at high cutting speeds as compared to conventional milling, whereas the norm is an exponential increase in tool wear at elevated speeds. According to research, the wear mechanisms and mechanical issues of Ti6A14V still require thorough study [16]. Furthermore, it is indicated [17] that additional research

Table 2 Milling conditions and parameters of experiments

\begin{tabular}{ll}
\hline Parameter & Condition \\
\hline Cutting speed $\left(V_{\mathrm{c}}\right)$ & $100-500 \mathrm{~m} / \mathrm{min}$ \\
Feed/tooth $\left(f_{\mathrm{z}}\right)$ & $0.025,0.0375$, and $0.05 \mathrm{~mm} / \mathrm{z}$ \\
Depth of cut $\left(a_{\mathrm{p}}\right)$ & $2 \mathrm{~mm}$ \\
Working engagement $\left(a_{\mathrm{e}}\right)$ & $0.5 \mathrm{~mm}$ \\
Coolant & Flood \\
\hline
\end{tabular}

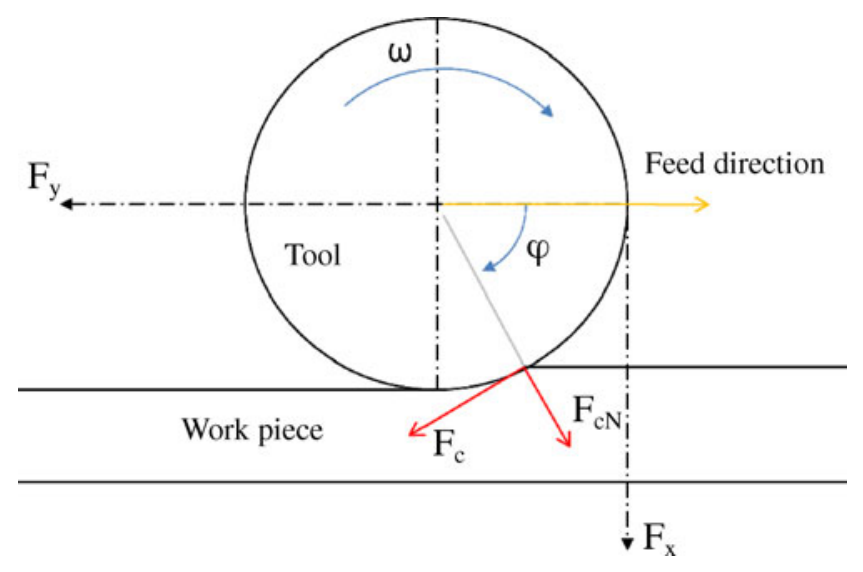

Fig. 1 Schematic view of shoulder milling process

is required to determine the dominant tool wear mechanisms of PCD tool material. The objective of this work is to analyze the tool wear progression and the cutting forces variation relative to cutting speed. Similarly, the main wear types for PCD milling Ti6A14V are studied.

\section{Nomenclature}

$V_{\mathrm{b}} \quad$ Flank wear land $(\mu \mathrm{m})$

$V_{\mathrm{c}} \quad$ Cutting speed $(\mathrm{m} / \mathrm{min})$

$f_{\mathrm{z}} \quad$ Feed per tooth (mm/tooth)

$h_{\mathrm{ex}} \quad$ Maximum chip thickness (mm)

$F_{x}, F_{y}, \quad$ Force components in $x$-, $y$-, and $z$-directions $(\mathrm{N})$

$F_{z}$

$F_{\mathrm{c}}, F_{\mathrm{cN}}$, Cutting, cutting perpendicular, and axial force

$F_{\mathrm{a}} \quad$ components $(\mathrm{N})$

$k_{\mathrm{c}} \quad$ Cutting coefficient $\left(\mathrm{N} / \mathrm{mm}^{2}\right)$

$a_{\mathrm{e}}, a_{\mathrm{p}} \quad$ Radial- and axial depth of cut (mm)

$\theta \quad$ Engagement angle (degree)

$\omega \quad$ Spindle rotational speed (rev/min)

$\varphi \quad$ Instantaneous angle position of the shoulder mill with respect to the negative $y$-direction and measured clockwise (degree)

$\varphi_{\text {st }} \quad$ Entry angle of tool (degree)

$\varphi_{\mathrm{ex}} \quad$ Exit angle of tool (degree)

\section{Experimental procedure}

\subsection{Work material}

A Ti6Al4V (ASTM B265, grade 5) sample was used, with a hardness measured to be $360 \mathrm{HV}$ and a high ultimate tensile strength $(1,080 \mathrm{MPa})$ as indicated in Table 1 . This grade of 
Fig. 2 Wear progression of PCD at different cutting speeds $\left(f_{\mathrm{z}}=0.05 \mathrm{~mm} / \mathrm{z}\right)$

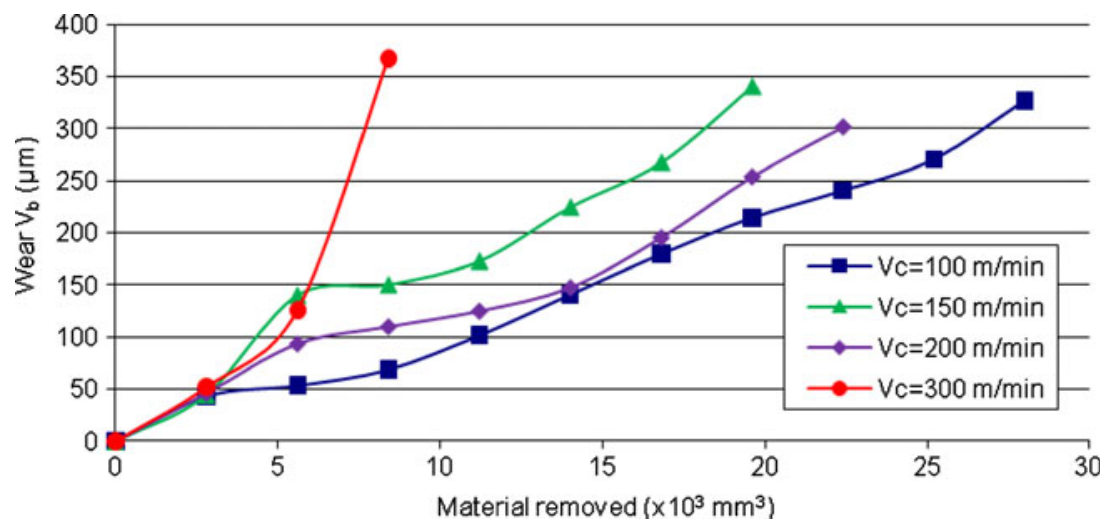

material was chosen to produce the most demanding conditions achievable when machining this alloy.

\subsection{Milling experiment}

Research [18] suggested a cutting speed in the range of 185 to $220 \mathrm{~m} / \mathrm{min}$ for titanium alloys and the chip load $\left(f_{\mathrm{z}}\right)$ below $0.05 \mathrm{~mm} \mathrm{[7]} \mathrm{to} \mathrm{reduce} \mathrm{the} \mathrm{possibility} \mathrm{of} \mathrm{catastrophic}$ tool failure in climb milling. Table 2 tabulates the cutting conditions for the experiments.

Experiments were done at cutting speeds ranging from 100 to $500 \mathrm{~m} / \mathrm{min}$ and feed rate of $0.025-0.05 \mathrm{~mm} / \mathrm{z}$. A Hermle C40U milling machine was used with a lubrication emulsion designed specifically for the cutting of titanium alloys. Due to the low modulus of elasticity of the workpiece, the length was limited to $280 \mathrm{~mm}$, in order to ensure rigid clamping of the material to minimize vibration. The PCD (CMX850) tools were examined after set cutting intervals, and the wear was continuously observed. The performance of the PCD was compared to that of coated carbide. The flank wear land $\left(V_{\mathrm{b}}\right)$ was analyzed with an optical microscope for dimensional measurements. The SEM was used for wear characterization, and the surface roughness was measured with a digital surface roughness meter. The failure criterion due to wear on the flank [11] was set for a maximum when $V_{\mathrm{b}}=0.3 \mathrm{~mm}$, and $R_{\mathrm{a}}=1.6 \mu \mathrm{m}$ [8] was used for surface roughness. Cutting forces are determined by the machined cross-section width and thickness, the cutting speed, and the tool wear. Figure 1 is a schematic view illustrating the experimental setup.

Once the force components in the $x$-, $y$-, and $z$-directions were measured with a Kistler $9255 \mathrm{~B}$ dynamometer, $F_{\mathrm{c}}, F_{\mathrm{R}}$, and $F_{\text {a }}$ could be expressed by the following transformation [19]:

$\left[\begin{array}{c}F_{\mathrm{c}} \\ F_{\mathrm{cN}} \\ F_{\mathrm{a}}\end{array}\right]=\left[\begin{array}{ccc}-\sin \varphi & \cos \varphi & 0 \\ \cos \varphi & \sin \varphi & 0 \\ 0 & 0 & 1\end{array}\right]\left[\begin{array}{l}F_{x} \\ F_{y} \\ F_{z}\end{array}\right]$

The entry angle of the tooth in the down milling operation, starting from the negative $y$-axis should be

$\varphi_{\mathrm{st}}=90^{\circ}-\cos ^{-1}\left[\left(R-a_{\mathrm{e}}\right) / R\right]$

The tooth exits the cutting segment at an angle of approximately $\varphi_{\mathrm{ex}}=90^{\circ}$, and the chip thickness is
Fig. 3 Tool life of PCD compared to the coated carbide at elevated cutting speeds

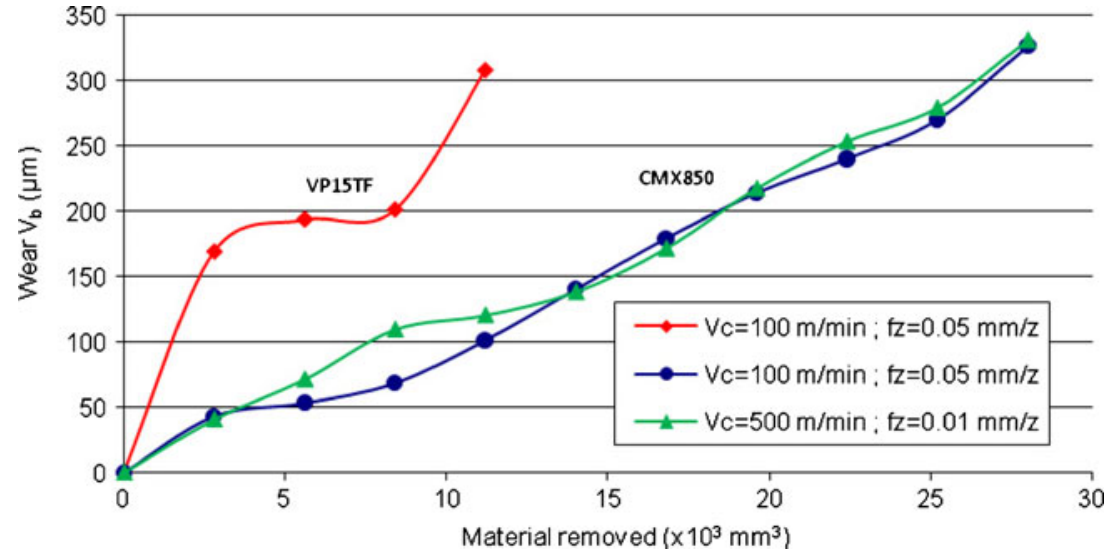


Fig. 4 Tool life of PCD and coated carbide $\left(f_{\mathrm{z}}=0.05 \mathrm{~mm} / \mathrm{z}\right)$

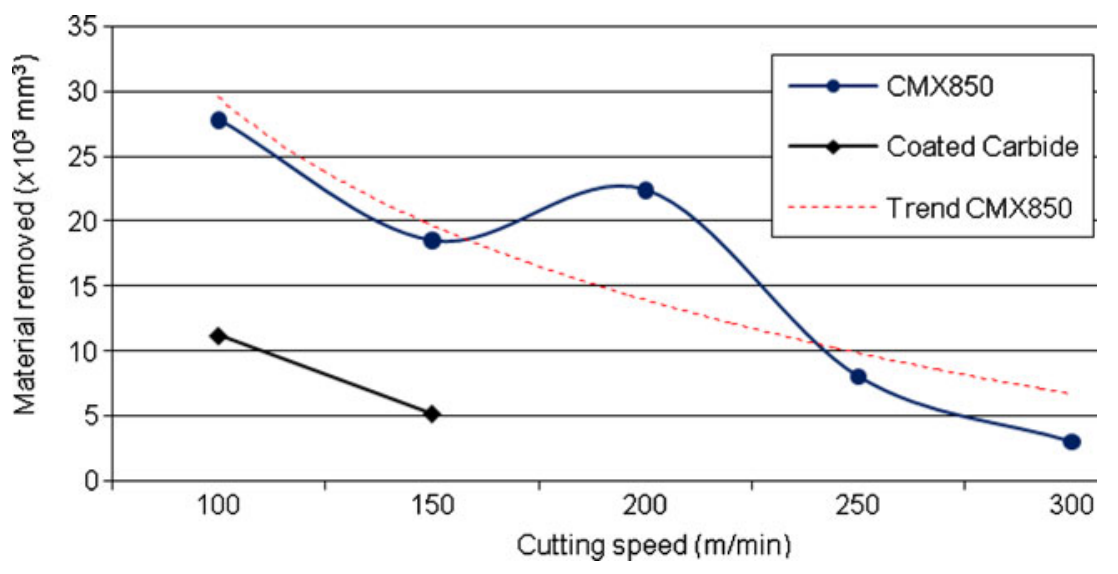

zero at this point. Thereby, Eq. 1 can be modified as follows:

$\left[\begin{array}{c}F_{\mathrm{c}} \\ F_{\mathrm{cN}} \\ F_{\mathrm{a}}\end{array}\right]=\left[\begin{array}{ccc}-\sin \varphi & \cos \varphi & 0 \\ \cos \varphi & \sin \varphi & 0 \\ 0 & 0 & 1\end{array}\right]\left[\begin{array}{l}F_{x} \\ F_{y} \\ F_{z}\end{array}\right]$ when $\varphi_{\mathrm{st}}<\varphi<\varphi_{\mathrm{ex}}$

The cutting coefficients $\left(k_{\mathrm{c}}\right)$ may be considered as a constant with respect to cutting speed for conventional cutting speeds, but under high-speed conditions, the value may decrease or increase due to thermal softening or strain rate hardening, respectively, as per Eq. 4 [20]:

$k_{\mathrm{c}}=\frac{F_{\mathrm{c}}}{h_{\mathrm{ex}} \times a_{\mathrm{p}}}$

\section{Results and discussion}

\subsection{Tool life}

The tools were examined after set cutting intervals, and the wear was continuously observed. The $V_{\mathrm{b}}$ was analyzed with an optical microscope for dimensional measurements, and the SEM was used for wear characterization. PCD was compared with a commercially available coated carbide material. The PCD performed satisfactorily for cutting speeds in the range of $100-200 \mathrm{~m} / \mathrm{min}$ with $f_{\mathrm{z}}=0.05 \mathrm{~mm} / \mathrm{z}$. As shown in Fig. 2, an increase in cutting speed resulted in sudden tool failure, because of the significant reduction in the strength and hardness of the tool material at elevated temperatures.

Lowering the feed rate to $0.01 \mathrm{~mm} / \mathrm{z}$ and increasing the cutting speed to $500 \mathrm{~m} / \mathrm{min}$ enabled the PCD to cut for similar extended tool life as when cutting at $100 \mathrm{~m} / \mathrm{min}$ $\left(f_{\mathrm{z}}=0.05 \mathrm{~mm} / \mathrm{z}\right)$, and a distinctly better surface finish was attained. The surface roughness measurements for the different cutting speeds all resulted in $R_{\mathrm{a}}<1$. At elevated cutting speeds, the PCD outperformed the benchmark coated carbide, which is illustrated in Fig. 3.

The failure of the coated carbide in the high temperature environment could be due to the lower hot hardness of the tool as depicted in the literature [1,2]. Figure 3 indicates the generally accepted decreasing trend in tool life, associated with an increase in cutting speed. For tool
Fig. 5 Measured cutting forces at different cutting speeds $\left(f_{\mathrm{z}}=\right.$ $0.05 \mathrm{~mm} / \mathrm{z}$ )

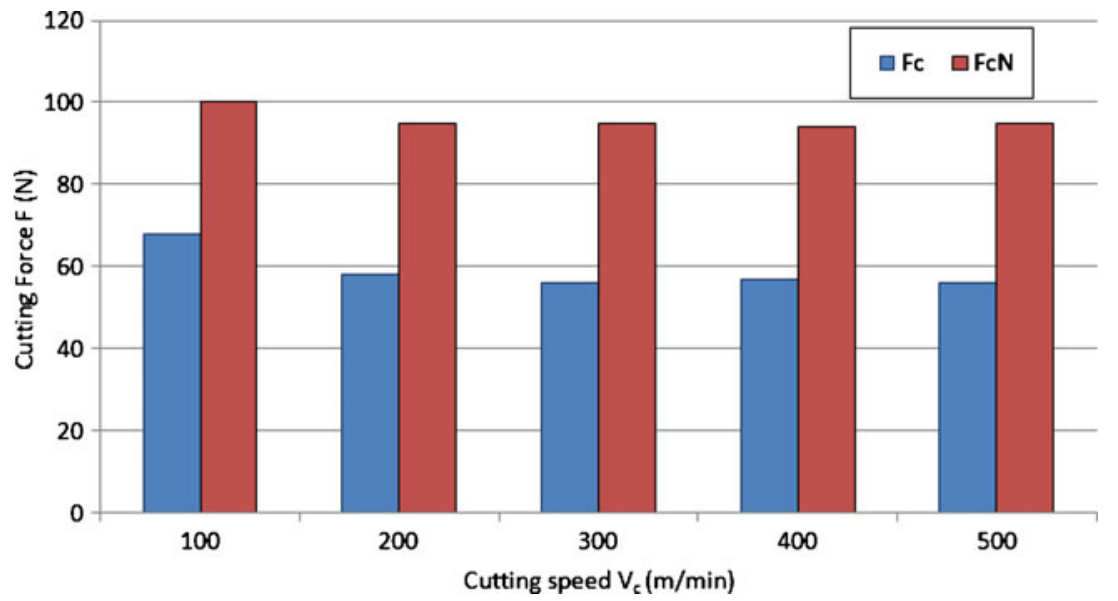


Fig. 6 SEM EDAX analysis of the material build-up on the PCD tool material; as supporting evidence, the build-up is Ti6Al4V

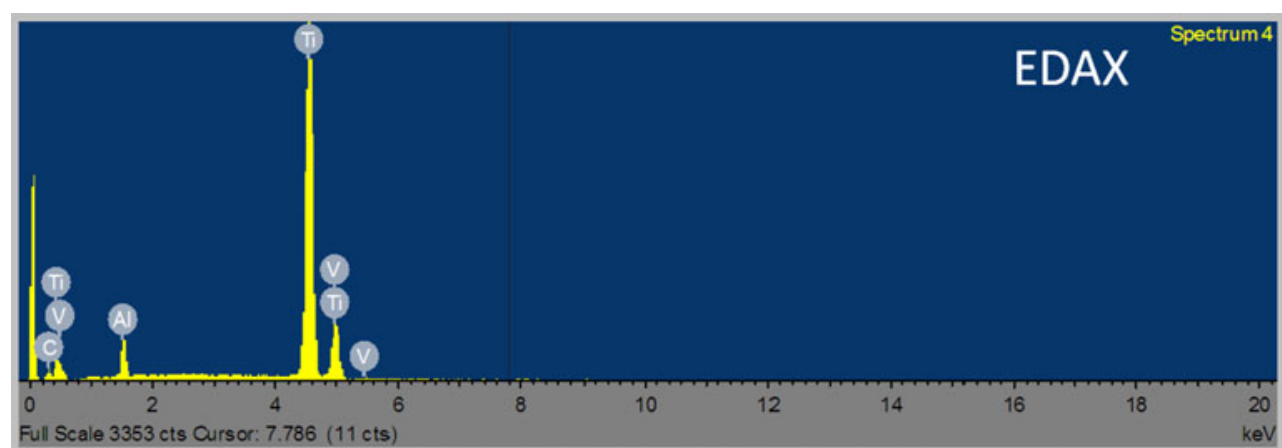

materials with lower transverse rupture strength, such as PCD compared to carbide, there may be a minimum cutting speed below which mechanical overload may occur. In the same way, a local maximum tool life may exist if there is a phase change in the workpiece material, and the insert can withstand the harsh operating conditions associated with the elevated temperature. This PCD proved that there is a definite increase in tool life, at a cutting speed of $200 \mathrm{~m} / \mathrm{min}\left(f_{\mathrm{z}}=0.05 \mathrm{~mm} / \mathrm{z}\right)$ compared to $150 \mathrm{~m} / \mathrm{min}$ (Fig. 4).

In this study, the tool life increased when the cutting speed was increased from 150 to $200 \mathrm{~m} / \mathrm{min}$. The literature shows that increasing the cutting speed beyond $200 \mathrm{~m} / \mathrm{min}$ will increase the cutting temperature significantly beyond $1,000^{\circ} \mathrm{C}$ [21]. The $\alpha$ phase (hexagonal close packed) of Ti6Al4V is hard and brittle, with a strong hardening tendency. The $\beta$ phase (body-centered cubic) is ductile and can be cut more easily, but also has a strong tendency to adhere [3]. The body-centered cubic structure has more slip systems, thereby reducing the yield stress for failure in shear [13]. Also, considering that the strength of Ti6Al4V is reduced from 1,000 MPa at ambient temperature to below $550 \mathrm{MPa}$ above $500^{\circ} \mathrm{C}$ [6], the explanation for this increase in tool life could be the phase transformation from $\alpha$ to $\beta$ phase, which occurs at about $950^{\circ} \mathrm{C}$ and above [22]. At a cutting speed of $250 \mathrm{~m} / \mathrm{min}$, the tool life was significantly reduced. Although the strength of the workpiece material is low at this cutting speed [22], the chemical attack on the tool is more aggressive. Thermal softening and chemical reactions weakened the intergranular bonds of the cobalt and diamonds in the PCD tool, which caused the grains to tear apart under the action of the machining shear stress.

Table 3 SEM EDAX analysis of the material build-up on the PCD tool material; as supporting evidence, the build-up is Ti6Al4V

\begin{tabular}{lllllll}
\hline In stats & $\mathrm{C}$ & $\mathrm{O}$ & $\mathrm{Al}$ & $\mathrm{Ti}$ & $\mathrm{V}$ & Total \\
\hline Weight $\%$ & 3.95 & - & 5.34 & 86.9 & 3.81 & 100 \\
\hline
\end{tabular}

\subsection{Cutting forces}

Cutting is a process of extensive stresses and plastic deformations. The high compressive and frictional contact stresses on the tool face result in substantial cutting force. Figure 5 illustrates the $F_{\mathrm{c}}$ for the different cutting speeds.

Similar to literature $[1,2,8,12]$, the cutting force decreased with an increase in $V_{\mathrm{c}}$ for CMX850. There is a noticeable reduction in cutting force when increasing the cutting speed from $V_{\mathrm{c}}=100$ to $V_{\mathrm{c}}=200 \mathrm{~m} / \mathrm{min}$. This is at the same cutting speed that resulted in slower wear progression with an increase in cutting speed. This step decrease in $k_{\mathrm{c}}$ from $2,400 \mathrm{~N} / \mathrm{mm}^{2}\left(V_{\mathrm{c}}=100 \mathrm{~m} / \mathrm{min}\right)$ to $2,085 \mathrm{~N} / \mathrm{mm}^{2}$ $\left(V_{\mathrm{c}}=200 \mathrm{~m} / \mathrm{min}\right)$ might be due to the new slip system after the phase change. A clear minimum of all cutting force components is discovered when finishing with $V_{\mathrm{c}}=300 \mathrm{~m} / \mathrm{min}$.

\subsection{Observations of tool wear}

SEM analysis was also employed in order to identify the build-up on the flank wear scar. The build-up on the PCD material was found to be Ti6A14V. Figure 6 illustrates the results of this analysis. Compared with the nominal $6 \%$ aluminum and $4 \%$ vanadium in Table 3, it becomes clear that the deposit is work material.

This was supported using image mapping with the SEM and its software as shown in Fig. 7.

An EDM sectioned sample gives an indication of the formed wear scar on the flank. Figure 8 indicates where the sample was cut and the form of the wear scar. The sample was $\times 350$ enlarged under the SEM.

As illustrated, the PCD tool was cut through the wear scar (section A-A) by means of electric discharge machining (EDM) and polished. The SEM on the sectioned sample yielded supportive information to establish that the depth of the wear on the flank to be around 20-25- $\mu$ m deep. Acid cleaning (hydrochloric acid) enabled that the true wear scar was exposed below the deposited Ti6Al4V layer on the flank. Post-acid cleaning SEM analysis revealed that a 
Fig. 7 Analysis of material build-up on the PCD using image mapping with the SEM, showing that the build-up is Ti6Al4V on the PCD tool material

Fig. 8 EDM sectioned wear scar showing the depth of the wear on the flank
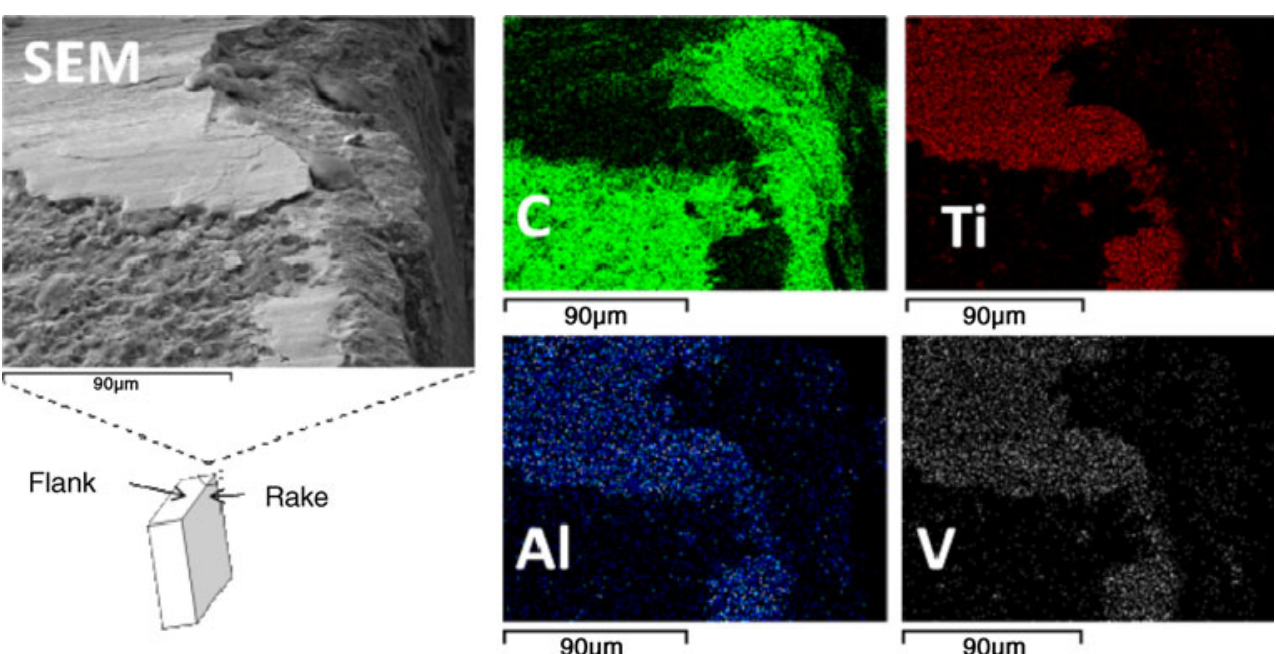

$90 \mu \mathrm{m}$

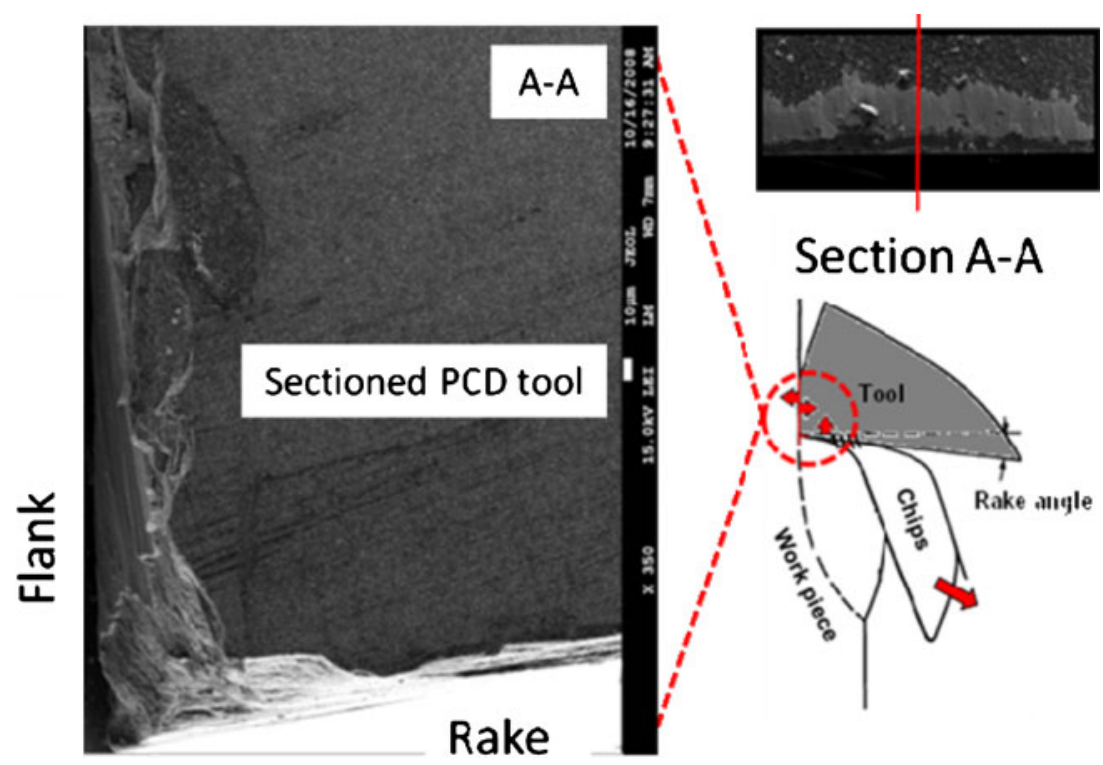

typical flank wear scar had different wear regions as illustrated in Fig. 9.

These different regions from the edge inward are as follows:

Region A: The highest load is exerted on the edge of the insert. This zone is where the initial chipping occurs, due to mechanical impact, and is measured to be around $45-\mu \mathrm{m}$ deep with the SEM.

Region B: This region is also characterized with impactrelated wear. The workpiece material tends to stick and break away under the cutting forces. This causes small particles to be gradually dislodged out of the diamond matrix.

Region C: This region was covered with a Ti6Al4V layer, and the region is characterized by a relatively

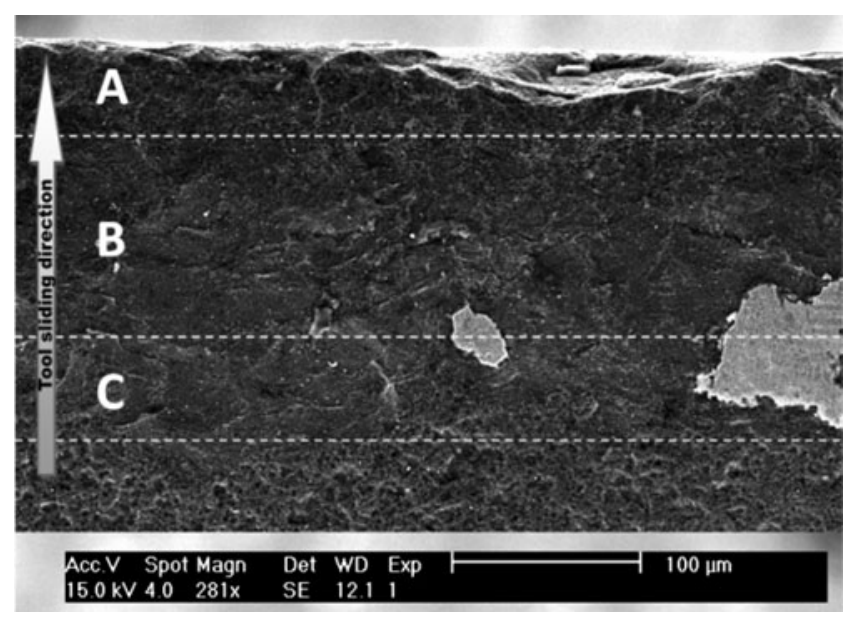

Fig. 9 Etched PCD wear scar on the flank illustrating the different wear regions 
smoother (polished) surface. The removed and adhered layers caused more adhesive rubbing, which is believed to increase the cutting temperature. This causes the workpiece to weld onto the wear scar. The critical temperature for adhesion to occur for machining with PCD is reported [23] to be roughly $760^{\circ} \mathrm{C}$, around which, the high temperature strength of PCD is believed [1] to be degrading as well. Also above $800^{\circ} \mathrm{C}$, the probability of chemical interaction of PCD with the workpiece material [6] increases.

\section{Conclusion}

The performance of PCD tools have been investigated in terms of tool life, surface roughness, cutting forces, and the wear mechanisms under different cutting conditions. Results from this study showed that for PCD, a decrease in feed and an increase in cutting speed $\left(V_{\mathrm{c}}\right)$ produced a better surface finish, while achieving a similar tool life when compared to lower speeds and higher feeds. PCD has outperformed the carbide tool at elevated cutting speeds. Complementary to the slower wear progression that was found at a cutting speed $200 \mathrm{~m} / \mathrm{min}$, the cutting force was also reduced by a significant amount. Observations based on SEM analysis suggested that adhesion of the workpiece took place during milling of Ti6Al4V, after which, degradation of the tool accelerated, probably due to the combined effect of thermal and mechanical wear.

Acknowledgements This research is funded by the Advanced Manufacturing Technology Strategy (AMTS) program, an initiative of the South African Department of Science and Technology (DST).

Open Access This article is distributed under the terms of the Creative Commons Attribution Noncommercial License which permits any noncommercial use, distribution, and reproduction in any medium, provided the original author(s) and source are credited.

\section{References}

1. Ezugwu EO, Bonney J, Yamane Y (2003) An overview of the machinability of aeroengine alloys. J Mater Process Technol 134:233-253

2. Rahman M, Wang Z-G, Wong Y-S (2006) A review on high-speed machining of titanium alloys. JSME Int J 49(1):11-20

3. Kuljanic E, Fioretti M, Beltrame L, Miani F (1998) Milling titanium compressor blades with PCD cutter. CIRP Ann 47(1):6164
4. Dearnley PA, Grearson AN (1986) Evaluation of principal wear mechanisms of cemented carbides and ceramics used for machining titanium alloy IMI 318. Mater Sci Technol 2(1):47-58

5. Kirk DC (1971) Cutting aerospace materials (nickel-, cobalt-, and titanium-based alloys). Rolls Royce Ltd, London, pp 77-98

6. Donarchie MJ Jr (2000) Titanium. A technical guide, 2nd edn. ASM International, The Materials Information Society, Materials Park

7. Barnett-Ritcey DD (2004) High-speed milling of titanium and gamma-titanium aluminide: an experimental investigation, $\mathrm{Ph} . \mathrm{D}$. thesis. McMaster University, Canada

8. Ezugwu EO, Bonney J, Da Silva RB, Cakir O (2007) Surface integrity of finished turned Ti-6Al-4 V alloy with PCD tools using conventional and high pressure coolant supplies. Int J Mach Tools Manuf 47:884-889

9. Konig W, Neises A (1993) Turning TiAl6V4 with PCD. Ind Diamond Rev 2:85-88

10. Sharman ARC, Aspinwall DK, Dewes, RC and Bowen P (2000) Tool life when turning gamma titanium aluminide using carbide and PCD tools with reduced depths of cut and high pressure fluid. Proceedings of the 28th NAMRC, pp 161-166

11. Nurul Amin AKM, Ismail AF, Nor Khairusshima MK (2007) Effectiveness of uncoated WC-Co and PCD inserts end milling of titanium alloy-Ti-6Al-4V. J Mater Process Technol 192 193:147-158

12. Wang ZG, Rahman M, Wong YS (2005) Tool wear characteristics of binderless CBN tools used in high-speed milling of titanium alloys. Wear 258:752-758

13. Komanduri R, Hou Z-B (2002) On thermoplastic shear instability in the machining of a titanium alloy (Ti-6Al-4V). J Metal Mater Trans 33(9):2995-3010

14. Su Y, He N, Li L, Li XL (2006) An experimental investigation of effects of cooling/lubrication conditions on tool wear in highspeed end milling of Ti-6Al-4V. Wear 261(7-8):760-766

15. Eckstein M, Lebküchner G, Blum D (1991) Schaftfräsen von Titanlegierungen mit hohen Schnittgeschwindigkeiten - Teil 1: Schruppen. VDI-Z 133(12):28-34 (In German)

16. Corduan N, Himbert T, Poulachon G, Dessoly M, Lambertin M, Vigneau J, Payoux B (2006) Wear mechanisms of new tool materials for Ti-6Al-4V high performance machining. Annals of the CIRP - Manufacturing Technology 52(1):73-76

17. Arsecularatne JA, Zhang LC, Montross C (2006) Wear and tool life of tungsten carbide, PCBN, and PCD cutting tools. Int J Mach Tools Manuf 46:482-491

18. Zoya ZA, Krishnamurthy R (2000) The performance of CBN tools in the machining of titanium alloys. J Mater Process Technol 100:80-86

19. Rotberg J, Shova S, Ber A (1997) Fast evaluation of cutting forces in milling, applying no approximate models. Int J Adv Manuf Technol 13:17-26

20. Abele E, Dietz S, Schiffler A (2009) Analysis of cutting force during milling with regards to the dependency on the penetration angle. Prod Eng Res Dev 3:483-487

21. Kikuchi M (2008) The use of cutting temperature to evaluate the machinability of titanium alloys. Division of Dental Biomaterials, Graduate School of Dentistry, Tohoku University, Sendai

22. Honnarat Y (1996) Issues and breakthrough in the manufacture of turboengine titanium parts. Mater Sci Eng Part A 213:115-120

23. Che-Haron $\mathrm{CH}$, Jawaid A (2005) The effect of machining on surface integrity of titanium alloy Ti-6\%Al-4\%V. J Mater Process Technol 166:188-192 